\title{
Parents' Satisfaction of Tele-Rehabilitation for Children with Neurodevelopmental Disabilities During the Covid-19 Pandemic
}

\author{
Pamela Frigerio \\ ASST GOM Niguarda \\ Liliana Del Monte \\ ASST GOM Niguarda \\ Aurora Sotgiu \\ ASST GOM Niguarda \\ Costantino De Giacomo \\ ASST GOM Niguarda
}

Aglaia Vignoli ( $\nabla$ aglaia.vignoli@unimi.it)

Università degli Studi di Milano

\section{Research Article}

Keywords: Parents' satisfaction, tele-rehabilitation, COVID-19, Neurodevelopmental disabilities.

Posted Date: August 30th, 2021

DOI: https://doi.org/10.21203/rs.3.rs-586652/v1

License: (c) (i) This work is licensed under a Creative Commons Attribution 4.0 International License. Read Full License 


\section{Abstract}

Background: The use of remote rehabilitation in children was limited before the COVID-19 pandemic, due to culture, technology access, regulatory and reimbursement barriers.

Methods: The study was conducted according to the STROBE (The Strengthening the Reporting of Observational Studies in Epidemiology) checklist in order to provide qualitative and quantitative data about experience of patients with disabilities and their caregivers during Phase 1 of the COVID-19 pandemic, and their level of satisfaction. An online survey was developed using Google Forms and sent via email. The outcome measures were rated using a 5-point Likert Scale. Two additional open-ended questions were used to collect qualitative data.

Results: 128 out of 261 families responded to the survey: $80.5 \%$ of the caregivers reported they were satisfied with the remote rehabilitation. More than a half $(53 \%)$ of the families reported a high level of satisfaction with the involvement they received in defining and sharing of rehabilitation goals.

Conclusions: The implementation of telehealth during the COVID-19 lockdown has allowed us to gain more information about the potential of tele-rehabilitation, and resulted in an excellent satisfaction of caregivers. With appropriate education and consistent models of care, an increased use of telehealth may provide advances in remote patient care.

Trial registration: Not applicable

\section{Background}

Following the spread of the COVID-19 outbreak in Italy in February 2020, strict measures have been implemented by the Italian Government. As a primary intervention to contain the SARS-CoV-2 infection spread, the Italian Government aimed at limiting the virus transmission by imposing a severe lockdown with daily-life restrictions and closure of educational, social, and manifacturing activities (1). Lombardy has been one of the epicenters in Italy and one of the regions that have been most severely affected by the pandemic in Europe. Regional Health Authorities have recognized children and adolescents with neurological/psychiatric disorders as a priority and have authorized the continuation of services for "Childhood and Adolescence Neuropsychiatric Units". They recommended interrupting standard and deferrable in-person rehabilitation therapies and/or integrating in-person rehabilitation sessions with remote therapy, to ensure continuity of care and to protect patients and healthcare professionals (2).

As a consequence, our Unit located at Niguarda Hospital in Milan (Italy) has been forced to rapid changes in the organization of rehabilitation care delivery, and new procedures have been developed in accordance to the national and regional emergency plans and recommendations. Since remote and virtual rehabilitation was not included into our routine care, we rapidly implemented policies and procedures in our outpatient services according to the current laws on informed consent, data protection, 
and privacy. During this state of emergency declared by the Italian Government, the policy on reimbursement was also adjusted.

In-person sessions for outpatient children for whom neuropsychiatric assessment was ongoing were postponed. Therapy continued remotely for outpatient children with ongoing rehabilitation programs, when the Individual Rehabilitation Project (IRP) allowed so. Tele-rehabilitation was delivered through different modalities, namely phone contacts, video calls, online platforms, videos sent to the families, and other devices available for remote contact.

Although remote rehabilitation has long been recognized as a promising means of providing rehabilitation therapy (3)(4)(5)(6)(7), the use of remote devices for rehabilitation in children was limited before the COVID-19 pandemic, due to culture, technology access, regulatory and reimbursement barriers (8)(9)(7). Now telemedicine is emerging as an indispensable resource to support the rehabilitation of patients and to ensure continuity of care. In keeping with the concept that this unprecedented period of healthcare crisis can also become an opportunity, we need to improve our ability to use innovative technologies to respond to the special healthcare needs of children with disabilities and their families $(10)(11)(12)(13)(14)$. To do this, we need to start to understand patients' and caregivers' perceptions, needs and levels of satisfaction.

The aim of this report is to provide qualitative and quantitative data about the level of satisfaction and experience by patients and caregivers during Phase 1 of the COVID-19 pandemic, when remote therapy emerged as the sole alternative to follow patients and to continue rehabilitation programs.

The secondary aim is to assess the association of caregivers' and patients' levels of satisfaction with other variables such as patients' age, type of rehabilitation program, and device used.

\section{Methods}

The study was conducted according to the CHERRIES (Checklist for reporting results of internet Esurveys) guidelines (15). After reviewing the existing literature as well as other data sources or surveys with similar research topics, we structured an online survey containing 15 items to investigate general information and 18 specific items with multiple choices. The content of the survey is available in the supplemental material - appendix. The outcome measures were rated using a 5-point Likert Scale.

The questions were divided into a first part with general information and a second battery of 18 items

divided into four sections: 1 . Remote rehabilitation tools; 2 . Communication and information; 3 . Ability to develop and execute a treatment plan; 4. General patient satisfaction. Two additional open-ended questions were used to collect qualitative data, permitting detailed and more meaningful answers. Respondents were given the opportunity to detail pros and cons of remote rehabilitation and to provide general feedback. Patients' demographic data and type of rehabilitation therapy were also collected. 
This study was approved by the Institution's Data Protection office and Communication and External Relations office, on behalf of Ethic Commettee (Comitato Etico Milano Area 3).

All parents of children receiving remote rehabilitation during the lockdown period were eligible to participate. Inclusion criteria were an ongoing IRP and at least one remote contact during the lockdown period (February-June 2020) with any rehabilitation professional from our Unit of Child and Adolescence Neuropsychiatry, Mother and Child Department, Niguarda Hospital, in Milan, Italy. Rehabilitation professionals included: physiotherapists, speech therapists, occupational therapists, neuropsychomotricist of the developmental age, professional educators, and psychiatric rehabilitation therapists.

Caregivers were informed about the initiative by the therapist during their remote therapy session. Those who agreed to participate received an informative email with a link to the online survey. Since the online survey was anonymous and carried out with the CAWI (Computer Assisted Web Interviewing) method, completing the survey was considered a form of consent and no additional written consent was deemed necessary for this initiative by the ethics committee. Usability and technical functionality of the electronic questionnaire had been tested before sharing the questionnaire with the families.

The study complied with institutional regulations for anonymized studies and adhered to the principles of the Helsinki Declaration.

The e-mail granted access to a single-use link to the survey, and was sent 20 weeks after the beginning of the remote intervention. Only one caregiver/parent was allowed to respond for each child.

We used an online survey tool through Google Moduli hosted on our Institution's Communication and External Relations office that allows automated exporting of results.

Results were collected in a dedicated database and exported to Microsoft Excel for validation and analyses.

\section{Statistical analysis}

Data were first submitted as customary descriptive statistics. Continuous variables were reported as mean ( \pm ) standard deviation or by median and range depending on the variable distribution, which was checked using the Shapiro-Wilk test. Various categorical variables were reported as relative and absolute frequency tables.

Statistical analysis was carried out using state/SE16.1.

Categorical variables were then checked by Fisher's exact test, while logistic regression was used to verify the dependence of binary variables on continuous and categorical variables.

\section{Results}


Between $6^{\text {th }}$ August, 2020 and $15^{\text {th }}$ October, 2020 we sent the link for completing the online survey to 261 families: 130 participated in the survey, and 128 responses were eligible for analysis.

Of the 128 responses, 99 (77.4\%) were given by mothers, $27(21 \%)$ by fathers and $2(1.6 \%)$ by other relatives.

Patients' and parents/caregivers' demographic data, patients' ages and diagnoses are reported in Table 1.

Table 1. Patients' and caregivers' demographic data and patients' diagnoses

\section{PATIENTS}

n (\%)

Age (years)
$6(4.5)$

$>14$

\section{Diagnosis}

Autism Spectrum Disorders

Cerebral Palsy

Genetic Syndromes

Behavioural and Emotional Disorders

Specific Learning disorder

Specific Language Disorder

Mixed specific developmental disorders

Specific developmental disorder of motor function

$16(6.15)$

\section{CAREGIVERS/PARENTS}

Age (years)

n (\%)
4 (3)

$28(22)$

70 (55)

$14(11)$

$6(4.5)$

3 (2.3)

19 (15)

63 (49.2)

$36(28)$

7 (5.5)

$56-65$

$7(5.5)$

n (\%)

45

(17.31)

11 (4.23)

Secondary

School

38 (14.62) High School

$67(52)$

34 (13.08) University

$42(33)$

32 (12.31)

49 (18.85)

Others 
Proposal of remote rehabilitation was offered to 119 families (93\% of respondents) for the first time during Phase 1 of the COVID-19 emergency.

Twelve (9\%) patients received physiotherapy treatments, 12 (9\%) educational intervention, $36(28 \%)$ speech therapy, 29 (23\%) psychomotor therapy, and 39 (31\%) Equine-Assisted Therapy.

Eighty-two households (64\%) owned a personal computer (PC), 30 (23\%) used a smartphone, and 16 $(13 \%)$ a tablet.

Data about platforms used and level of satisfaction regarding these means are reported in Table 2.

\section{Table 2. Platforms used and level of satisfaction}

\begin{tabular}{|c|c|c|c|c|c|c|}
\hline \multirow[t]{2}{*}{ Platforms } & \multirow[t]{2}{*}{$(\%)^{n}$} & \multicolumn{5}{|c|}{$\begin{array}{l}\text { Satisfaction level } \\
\text { n (\%) }\end{array}$} \\
\hline & & $\begin{array}{l}\text { Very } \\
\text { satisfied }\end{array}$ & Satisfied & $\begin{array}{l}\text { Partially } \\
\text { satisfied }\end{array}$ & Dissatisfied & $\begin{array}{l}\text { Very } \\
\text { dissatisfied }\end{array}$ \\
\hline Skype & $\begin{array}{l}85 \\
(66)\end{array}$ & $22(26)$ & $50(59)$ & $10(12)$ & $3(3)$ & 0 \\
\hline WhatsApp & $10(8)$ & $2(80)$ & $1(10)$ & $1(10)$ & 0 & 0 \\
\hline Meet & $3(2)$ & 0 & 2 (33) & $1(67)$ & 0 & 0 \\
\hline Zoom & $1(1)$ & 0 & $1(100)$ & 0 & 0 & 0 \\
\hline $\begin{array}{l}\text { Multiple } \\
\text { platforms }\end{array}$ & $\begin{array}{l}16 \\
(13)\end{array}$ & $5(31)$ & $10(63)$ & $1(6)$ & 0 & 0 \\
\hline No platforms & $\begin{array}{l}13 \\
(10)\end{array}$ & $5(38)$ & $6(46)$ & $1(8)$ & $1(8)$ & 0 \\
\hline
\end{tabular}

The whole cohort received parent-child educational sessions, 112 (88\%) families received video calls, 12 (9\%) were called through phone calls, and 4 (3\%) were sent tools to perform the therapies (e.g. videos, drawings, pictures) between therapist and family.

In terms of management of computer tools, 86 (67\%) patients were not independent. Therefore, 59 (46\%) caregivers were asked to attend the entire session.

Data from the "Communication and Information" section (level of satisfaction with the information received, availability of staff, involvement and clarity of the language used by therapists) are reported in Table 3.

Table 3. Communication and Information section and level of satisfaction 
n (\%)

\begin{tabular}{llcccc} 
& $\begin{array}{l}\text { Very } \\
\text { satisfied }\end{array}$ & Satisfied & $\begin{array}{c}\text { Partially } \\
\text { satisfied }\end{array}$ & Dissatisfied & $\begin{array}{l}\text { Very } \\
\text { dissatisfied }\end{array}$ \\
\hline $\begin{array}{l}\text { Information received by } \\
\text { therapists }\end{array}$ & $74(58)$ & $\begin{array}{c}50 \\
(39)\end{array}$ & $4(3)$ & 0 & 0 \\
\hline $\begin{array}{l}\text { Availability of therapists with } \\
\text { regard to the organization }\end{array}$ & $87(68)$ & $35(27)$ & $6(5)$ & 0 & 0 \\
\hline $\begin{array}{l}\text { Involvement in defining the } \\
\text { activities }\end{array}$ & $68(53)$ & $47(37)$ & $9(7)$ & $4(3)$ & 0 \\
$\begin{array}{l}\text { Clarity of the language used by } \\
\text { therapists }\end{array}$ & $80(63)$ & $44(34)$ & $4(3)$ & 0 & 0 \\
\hline
\end{tabular}

Among caregivers, 39 (30.5\%) were very satisfied with the remote rehabilitation and $64(50 \%)$ were satisfied, for a total of $80.5 \%$ of the caregivers (including very satisfied and satisfied) [95\% Conf. Interval]. Conversely, 18 (14\%) caregivers were partially satisfied and 7 (5.5\%) dissatisfied. None of the caregivers reported that they were very dissatisfied.

Logistic regression showed no influence of the answer to the question level of satisfaction of remote rehabilitation" (Question 33) on the dichotomized answer to the question "caregiver's participation in the therapy session" (Question 14) [likelihood ratio test: $p=0.1899$ ], even though there was a statistically significant association between the dichotomized answer to Question number 33 and the dichotomized answer to Question number 14 (Fisher's exact test: $p=0.048$ ).

More than a half $(68.5 \%)$ of the families reported a high level of satisfaction with the involvement received in the definition and sharing of rehabilitation goals, 47 (37\%) stated that they were satisfied, 9 (7\%) partially satisfied, 4 (3\%) dissatisfied, 0 very dissatisfied.

Concerning the achievement of work objectives provided by the IRP, 42 (32\%) families were very satisfied, 69 (53\%) satisfied, 13 (10\%) partially satisfied, 6 (5\%) dissatisfied, 0 very dissatisfied.

Satisfaction with remote rehabilitation in relation to the child's ability to participate was rated as excellent by $70.3 \%$ of respondents [95\% Conf. Interval].

Satisfaction degree of remote rehabilitation in relation to the child's ability to participate according to age groups and to type of rehabilitation program are reported in Table 4.

The qualitative remarks at the end of the survey (open-ended questions) showed that many participants described the availability of the therapists as a positive aspect (30 families), as well as the continuity of the rehabilitation projects (20 families). Three caregivers expressed their desire to continue using video calls for meetings or therapies. 
Table 4 Satisfaction degree of remote rehabilitation in relation to the child's ability to participate analyzed by age groups and by type of rehabilitation program.

\begin{tabular}{|c|c|c|c|c|c|c|}
\hline \multirow[t]{2}{*}{ Age (years) } & \multirow[t]{2}{*}{$(\stackrel{n}{\%)}$} & \multicolumn{5}{|c|}{$\begin{array}{l}\text { Satisfaction level } \\
\text { n (\%) }\end{array}$} \\
\hline & & $\begin{array}{l}\text { Very } \\
\text { satisfied }\end{array}$ & Satisfied & $\begin{array}{l}\text { Partially } \\
\text { satisfied }\end{array}$ & Unsatisfied & $\begin{array}{l}\text { Very } \\
\text { unsatisfied }\end{array}$ \\
\hline$<2$ & $\begin{array}{l}6 \\
(4,5)\end{array}$ & $1(17)$ & $4(67)$ & $1(17)$ & 0 & 0 \\
\hline $2-2,11$ & $4(3)$ & 0 & $1(25)$ & $2(50)$ & $1(25)$ & 0 \\
\hline $3-5,11$ & $\begin{array}{l}28 \\
(22)\end{array}$ & $10(36)$ & $15(53)$ & $3(11)$ & 0 & 0 \\
\hline $6-10,11$ & $\begin{array}{l}70 \\
(55)\end{array}$ & $32(46)$ & $11(15)$ & $25(36)$ & $2(3)$ & 0 \\
\hline $11-13,11$ & $\begin{array}{l}14 \\
(11)\end{array}$ & 4 (29) & $8(57)$ & $1(7)$ & $1(7)$ & 0 \\
\hline$>14$ years & $\begin{array}{l}6 \\
(4,5)\end{array}$ & 0 & $5(83)$ & $1(17)$ & 0 & 0 \\
\hline
\end{tabular}

Type of rehabilitation $\quad$ Satisfaction level

(\%)

\begin{tabular}{|c|c|c|c|c|c|c|}
\hline & \multirow[t]{2}{*}{ (\%) } & \multicolumn{5}{|l|}{$\mathrm{n}(\%)$} \\
\hline & & $\begin{array}{l}\text { Very } \\
\text { satisfied }\end{array}$ & Satisfied & $\begin{array}{l}\text { Partially } \\
\text { satisfied }\end{array}$ & Unsatisfied & $\begin{array}{l}\text { Very } \\
\text { unsatisfied }\end{array}$ \\
\hline Physiotherapy & $\begin{array}{l}11 \\
(9)\end{array}$ & $3(27)$ & $6(55)$ & $1(9)$ & $1(9)$ & 0 \\
\hline Speech therapy & $\begin{array}{l}36 \\
(28)\end{array}$ & $16(45)$ & $16(44)$ & $3(8)$ & $1(3)$ & 0 \\
\hline $\begin{array}{l}\text { Educational } \\
\text { Intervention }\end{array}$ & $\begin{array}{l}13 \\
(10)\end{array}$ & $3(23)$ & $8(61)$ & $1(8)$ & $1(8)$ & 0 \\
\hline $\begin{array}{l}\text { Neuropsycomotor } \\
\text { Therapy }\end{array}$ & $\begin{array}{l}30 \\
(23)\end{array}$ & $7(23)$ & $14(47)$ & $9(30)$ & 0 & 0 \\
\hline Therapeutic Riding & $\begin{array}{l}39 \\
(30)\end{array}$ & $18(46)$ & $15(38)$ & $5(13)$ & $1(3)$ & 0 \\
\hline
\end{tabular}

\section{Discussion}

Children with neurodevelopmental disabilities and their families are at risk of developing psychological stress related to the COVID-19 pandemic and especially to the lockdown, which may determine the interruption of rehabilitation services (16). After recognizing the needs of these fragile individuals, with 
the support of Regional Health Authorities, we have developed specific supportive services that can be provided even remotely.

Since these tools have been supplied for the very first time during the pandemic in the great majority of patients, we thought that it would be particularly important to assess whether this new healthcare modality was responding to the patients' needs, by evaluating parents' satisfaction.

A particularly useful tool for the assessment of parents' satisfaction is a questionnaire-based survey, because parents can answer questions anonymously and do not have to fear negative consequences because of their opinion. Moreover, self-administered questionnaires are - in contrast to interviews cheaper, faster, and regarded as more voluntary (17).

Our study indicates that remote rehabilitation of children with neurodevelopmental disabilities through telemedicine is feasible and well accepted by the families. Indeed, $80.5 \%$ of them reported that they were satisfied with remote rehabilitation. The possibility to continue treatment during the pandemic and the availability of therapists from remote were considered the main advantages.

These findings are in line with previous preliminary data (18) (19) (20), which suggest that an emergency program that provides continuity of care and support with remote rehabilitation interventions may be beneficial for both the child's and the parents' well-being, with limited practical challenges.

Our direct experience during the pandemic demonstrates that tele-medicine in child neuropsychiatry produces positive effects for both the children and the families. On the child-side, we promoted and enabled continuity of care, maintained social contacts with their therapists, and reduced the risk of disrupting daily and weekly routines. Moreover, involving the parents in rehabilitation programs may improve the overall degree of satisfaction. Indeed, our experience confirms that the parents' role in facilitating the rehabilitation interventions is much more prominent using an online modality, as they can be more actively engaged by the therapists, thus increasing their self-esteem in parenting. Besides, by being closer to their own needs and those of their children, we were able to support the parents for both psychological and educational aspects (18).

The sample included in the present survey was highly representative of the usual customers of Italian Childhood and Adolescence Neurology and Psychiatry Units, and all the features of in-person rehabilitation that are usually offered have been covered remotely, although through innovative tools.

The development of specific rehabilitation tools created by the therapists has allowed to translate to remote also therapies where physical contact is very relevant. An example is that of Equine-Assisted Therapy, where the therapists made video calls from the Department and created specific videos to maintain goals about the ability to relate and on self-care. Customized materials have been developed for Augmentative Alternative Communication purposes. For instance, an interactive PowerPoint file dedicated to the horse theme was created to allow working on communication skills, attention, concentration, and alternation. Based on the results of the survey, we can infer that the relationship with 
the horse combined with a careful reformulation of the proposals has allowed maintaining high motivation to treatment despite the distance. As a result, $84 \%$ of the families rated positively the EquineAssisted Therapy with regard to the child's ability to participate, and positive evaluations were recorded for other types of intervention as well.

The tools available to the families and the channels that were used were investigated in order to evaluate the accessibility to the remote rehabilitation proposal: on-line platforms, e.g. Skype, were indicated as the most adequate instruments for rehabilitation purposes.

Considering that this was the first experience of tele-rehabilitation for almost the entire sample, we anticipated there would be some limits and critical issues. Therefore, we assessed data from Sect. 2 of the questionnaire (communication and information) to evaluate the effectiveness of the information received by the families.

In order to understand whether some treatments carry more issues or pitfalls than others and can therefore be more difficult to convert to remote rehabilitation, we analyzed the data about the child's ability to participate and the data about general satisfaction for each type of rehabilitation program. Some disciplines may be more challenging to be performed through tele-therapy (namely musculoskeletal work) and may require teaching of facilitation techniques to caregivers. In this view, the possibility to share previously recorded videos of rehabilitation sessions may help the families by supplying useful examples for continuity of care.

Moreover, children with behavioral or attention problems may face more difficulties following telerehabilitation sessions rather than face-to-face engagement.

One limitation of remote rehabilitation that emerged from our survey is the child's age, especially age younger than 3 years, even though the children in this age group were too few to permit further interpretation. As a matter of fact, toddlers need face-to-face rehabilitation treatments because of the importance of physical and relational contact. Indeed, they need treatments like physiotherapy or psychomotor therapy, where the physical and relational contact is crucial.

Even though limited to the COVID-19-related lockdown, the findings of our survey indicate a positive response of caregivers of children with neurodevelopmental disabilities to remote rehabilitation. This result may encourage policy makers to implement these services into future healthcare models, recognizing the reduced costs of care and high patient/caregivers' level of satisfaction.

\section{Conclusions}

The usual care of children with special needs has become even more challenging during the COVID-19 lockdown, since parents found themselves involved throughout the whole day and often without the support of educational and rehabilitation services. The feeling of being alone in direct caregiving of children with disabilities may result in frustrations and psychological stress. 
To mitigate these effects, we have developed potentially effective strategies to support the families of children with disabilities using tele-medicine approaches. This experience has allowed us to gain more information about the potentiality of tele-rehabilitation and resulted in an excellent level of satisfaction of the caregivers. With appropriate education and consistent models of care, an increased use of telehealth may provide advances in remote patient care.

\section{Abbreviations}

IRP: Individual Rehabilitation Project

CAWI: Computer Assisted Web Interviewing

\section{Declarations}

Ethics approval and consent to participate: Not applicable

Consent for publication: Not applicable

Consent statement: This study was approved by the Institution's Data Protection office and Communication and External Relations office. Written consent was not required since completing the survey was considered a form of consent.

Availability Of Data And Materials: The datasets used and analysed during the current study are available from the corresponding author on reasonable request

Competing interests: The authors declare no competing interests.

Funding: The work did not receive any financial support.

Authors' contributions: PF designing the study, LDM and AS initiating and monitoring the study, CDG monitoring progress of the study, AV guarantor of the study.

All the authors contributed in writing the paper.

\section{Acknowledgements}

The authors would like to thank the families for participating in this study and the Communication and External Relations Office of GOM Niguarda for their support in developing the on-line survey.

\section{References}

1. Government of Italy. Decree of the president of the Council of Ministers. mar 9, 2020.

2. Regional Health Lombardy Welfare DGR N. 3351 del 14/03/2020. "Supplementary provisions in implementation of DGR No. XI / 2906 of 8/03/2020 for the organization of the hospital network in 
order to the epidemiological emergency from COVID-19".

3. Burke, B. L., Hall, R. W., \& The Section on Telehealth Care. Telemedicine: Pediatric applications. Pediatrics. 1, e293-308 (2015).

4. Crutchley, S., Campbell, M. Telespeech therapy pilot project: Stakeholder satisfaction. International Journal of Telerehabilitation. 1, 23-30 (2010).

5. Tenforde, A. S., Hefner, J. E., Kodish-Wachs, J. E., laccarino, M. A., Paganoni, S. Telehealth in physical medicine and rehabilitation: A narrative review. The Journal of Injury, Function, and Rehabilitation. 55, S51-8 (2017).

6. Sutherland, R., Trembath, D., \& Roberts, J. Telehealth and autism: A systematic search and review of the literature. Int J Speech Lang Pathol. 3, 324-36 (2018).

7. Tanner, K. et al. Feasibility and Acceptability of Clinical Pediatric Telerehabilitation Services. International Journal of Telerehabilitation. 12, 43-52 (2020).

8. Dorsey, E. R., \& Topol, E. J. State of telehealth. The New England Journal of Medicine. 375, 154-61 (2016).

9. Tomines, A. Pediatric telehealth: Approaches by specialty and implications for general pediatric care. Advances in Pediatrics. 66, 55-85 (2019).

10. Badawy, S. M., \& Radovic, A. Digital approaches to remote pediatric health care delivery during the COVID-19 pandemic: Existing evidence and a call for further research. JMIR Pediatrics and Parenting. 1, e20049 (2020).

11. Ben-Pazi, H., Beni-Adani, L., Lamdan, R. Accelerating telemedicine for cerebral palsy during the COVID-19 pandemic and beyond. Frontiers Neurology.11, 746 (2020).

12. Ohannessian, R., Duong, T. A., Odone, A. Global telemedicine implementation and integration within health systems to fight the COVID-19 pandemic: A call to action. JMIR Public Health and Surveillance. 2, e18810 (2020).

13. Olayiwola, J. N., et al. Telehealth as a bright spot of the COVID-19 pandemic: Recommendations from the virtual frontlines ("frontweb"). JMIR Public Health and Surveillance. 2, e190445 (2020).

14. Wijesooriya, N.R., Mishra, V., Brand, P.L.P., Rubin, B.K. COVID-19 and Telehealth, Education, and Research Adaptations. Paediatric Respiratory Reviews. 35, 38-42 (2020).

15. Eysenbach G. Improving the quality of Web surveys: the Checklist for Reporting Results of Internet ESurveys (CHERRIES). J Med Internet Res. 3, e34 (2004).

16. Fazzi, E., Galli, J. New clinical needs and strategies for care in children with neurodisability during COVID-19. Dev Med Child Neurol.7, 879-80 (2020).

17. Weissenstein, A., Straeter, A., Villalon, G., Luchter, E., Bittmann, S. Parent satisfaction with a pediatric practice in Germany: a questionnaire-based study. Ital J Pediatr. 37, 31 (2011).

18. Provenzi, L., Grumi, S. and Borgatti R. Alone With the Kids: Tele-Medicine for Children With Special Healthcare Needs During COVID-19 Emergency. Frontiers Psychology. 11, 1-6 (2020). 
19. Provenzi, L., et al. Engaging with Families through On-line Rehabilitation for Children during the Emergency (EnFORCE) Group Italian parents welcomed a telehealth family-centred rehabilitation programme for children with disability during COVID-19 lockdown. Acta Paediatr. 00:1-3 (2020).

20. Tenforde, A.S., et al. Outpatient Physical, Occupational, and Speech Therapy Synchronous Telemedicine: A Survey Study of Patient Satisfaction with Virtual Visits During the COVID-19 Pandemic. Am J Phys Med Rehabil. 11, 977-81 (2020).

\section{Supplementary}

Appendix is not available with this version 